\title{
早孕大鼠子宫䧳二醇受体的苂光 组织化学观察
}

任惠民章生艮

(中国科学院上海生理研究所)

杨以谦吴晓云

(上海市计划生育科学研究所)

荻光标记雌二醇用于组织化学探测雌激素受体, 比 ${ }^{3} \mathrm{H}$-雌二醇具有更为简捷、直观的优 点. 我们合成了 4-亚氨基- $\mathrm{N}$-异硫氮酸荧光素 $17 \beta$-蜼二醇(简称 4NHEF), 曾半定量地测定 了大鼠子宫对 $4 \mathrm{NHEF}$ 的结合力, 并用雌二醇及 $4 \mathrm{NHEF}$ 对大鼠子官匀浆受体蛋白的竞争结合 以及 4NHEF 和 FITC 对非靶组织的对照比较等方法, 初步论证了 4NHEF 对雉二醇受体是 专一结合的试剂 ${ }^{[\mathrm{J}}$. 本文利用 $4 \mathrm{NHEF}$ 对成年大鼠子宫冰冻切片的雌二醇受体进行了检测, 研究了妊娠早期子宫㖺伊红细胞雌二醇受体含量与分布的变化，同时对此方法进一步做了论 证.

我们选用的实验动物是体重 200-300 克的成年膗性大鼠，在与雄性合笼后，每天早晨对 雌鼠作阴道涂片检查, 发现精子的当天, 作为弤娠 1 天. 本实验收集了妊娠 1-8 天 $\left(D_{1}-D_{8}\right)$ 的标本. 取材方法是将大鼠用戊巴比妥钠麻醉后, 迅速取下中段子宫, 长度约 8 毫米. 按照 $D_{6}$ 时胚泡着床的生理机制, 用 $1 \%$ 伊文思蓝静脉注射来显示着床点. $D_{6}$ 以后的标本均取子宫 还胎间组织. 将所取子宫置于干冰冷却的异伐烷中骧冷, 随即用封闭式冰冻切片机切片, 厚度 约 $8 \mu$ 。检测方法是将干冰中保存的冰冻切片取出, 减压抽干,待其恢复近至室温, 放置在湿盒 内, 将含 $0.02 \%$ 牛血清白蛋白 $\mathrm{pH} 7.3$ 的 $0.1 \mathrm{M}$ Tris- $\mathrm{HCl}$ 缓冲液配制的 $3 \times 10^{-8} \mathrm{M} 4 \mathrm{NHEF}$ 滴 加于切片表面上, $4^{\circ} \mathrm{C}$ 左右放置 $1.5-2$ 小时, 用 Tris- $\mathrm{HCl}$ 缓冲液洗净切片上残留的试剂后, 即可在荧光显微镜下进行观察, 根据切片显示的荧光受体数量, 由多到少依次分为六级, 即 $4+, 3+、 2+、 1+、 \pm$ 和 0 . 结果表明, 弤娠早期大鼠子宫嘹伊红细胞膗二醇受体, 主要分 布在子官内膜间质, 纵肌中数量不多, 环肌中比较少见, 此外, 腔上皮未显示雌二醇受体, 如图 $1 \mathrm{a}-e$ 所示. 肧胎在着床前, 特别 $D_{1} 、 D_{2}$ 时, 子宫嘫伊红细胞蜼二醇受体为 $3+-4+;$ 在 $D_{4}-$ $\mathrm{D}_{6}$ 时, 受体逐渐减少, 数量为 $1+-2+$; 胚胎着床后的 $\mathrm{D}_{7}-\mathrm{D}_{8}$ 时, 倠二醇受体含量明显地下 降, 数量为土甚至为零. 另外我们还注意到在妊娠过程中, 倠二醇受体的分布也呈现出一定的 规律性, 即越近宫腔部分, 受体消失得越早. 如图 $1 \mathrm{c}$ 所清楚显示的, $\mathrm{D}_{4}$ 时雌二醇受体存留部位 已是靠近环肌的间质区域,近官腔区域的受体已不复存在. 经过苏木精、伊红对 4 NHEF 所染 切片的复染 (图 1f), 我们发现 4NHEF 所显示的子宫嘹伊红细胞雌二醇受体与用 ${ }^{3} \mathrm{H}-$-雌二醇 对大鼠子官切片进行放射自显影定位雌二醇受体 ${ }^{[2,3]}$ 所获得的结果是相符的.

本文1983 年3月7日收到。

第 21 期

科学 通报

1331 
为了进一步证实此方法的可靠性, 我们对 4 NHEF 的生物活性及特异性作进一步论证, 开 展了竞争试验及与 $E_{2} R$ 抗体对照试验。

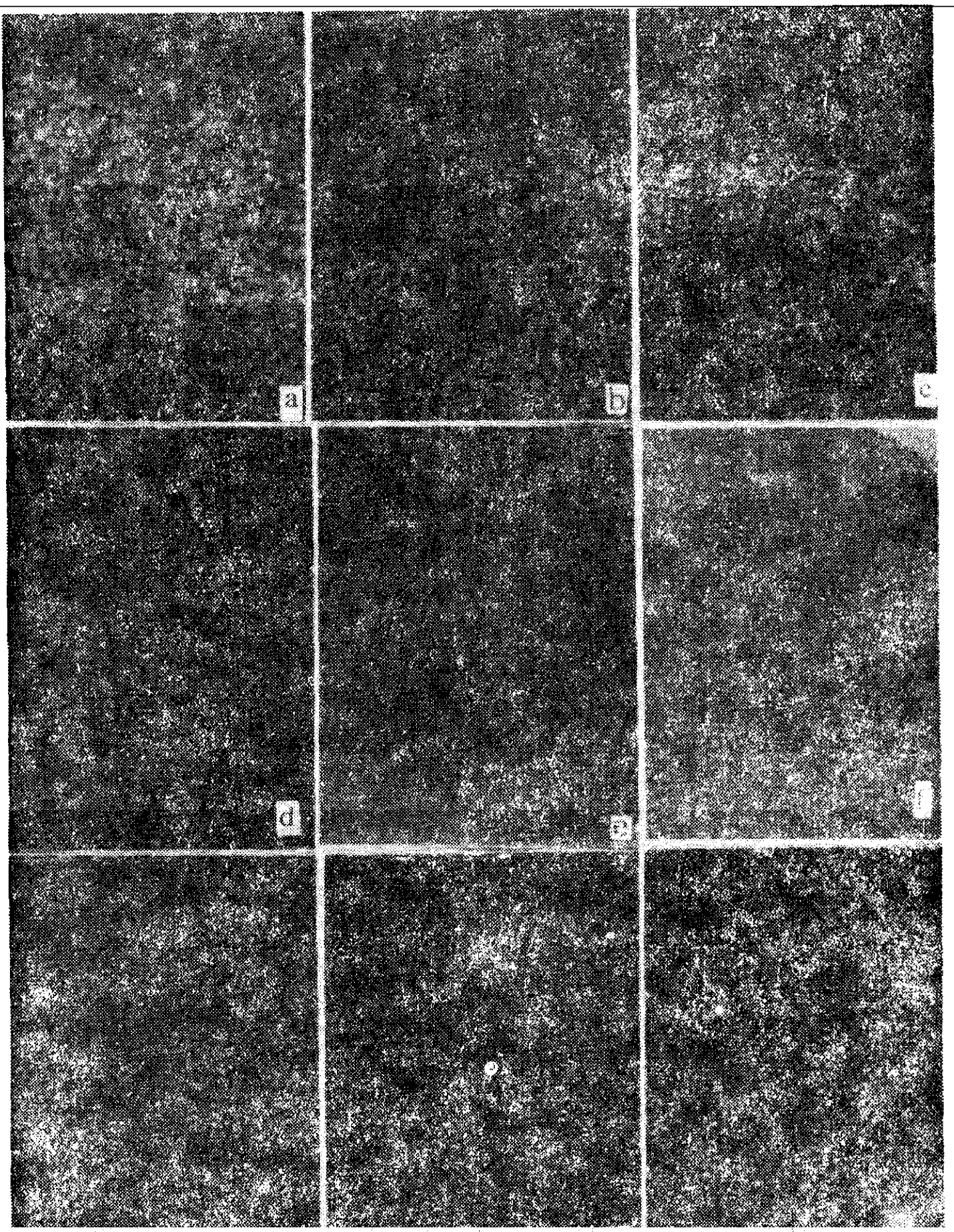

图 1 早骂大鼠子宫 $\mathrm{E}_{2}$ 受体的分布.与变化

4NHEF 染色: a. $D_{1} ;$ b. $D_{2} ;$ c. $D_{4} ;$ d. $D_{7} ;$ e. $D_{8} ;$ f. H/E 复染; g. 4NHEF 染色; b. 4NHEF/

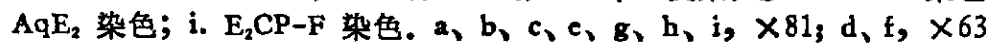

在竞争试验中, 我们分别用 4 NHEF 试剂以及 4 NHEF-水溶性雌二醇衍生物混合试剂染 相邻的子官冰冻切片, 在苂光显微镜下清楚观察到 $4 \mathrm{NHEF}$ 所染的切片 (图 $1 \mathrm{~g}$ ), 呈现明亮的 黄绿色荻光亮点, 而 $4 \mathrm{NHEF}$-水溶性雌二醇衍生物混合试剂所染的切片(图 $1 \mathrm{~h}$ ) 却表现出苂 
光亮度的减弱, 这表明 $4 \mathrm{NHEF}$ 具有良好的踓激素生物活性. 关于对照试验, 我们分别用 4 NHEF 及日本抗体研究所生产的: 异硫氧酸荧光素标记雌二醇受体抗体 (简称 $\mathrm{E}_{2} \mathrm{CP}-\mathrm{F}$ ) 染相 近的子宫冰冻切片, 亦观察到用 $\mathrm{E}_{2} \mathrm{CP}-\mathrm{F}$ (图 $1 \mathrm{i}$ ) 或 $4 \mathrm{NHEF}$ 所染的切片均显示出明亮的苂光 亮点,两者且有相同的几何形状与分布部位,这说明 $4 \mathrm{NHEF}$ 与 $\mathrm{E}_{2}$ 受体是特异结合的.

总而言之, 从上述的实验中, 我们不仅用 $4 \mathrm{NHEF}$ 对早孕大鼠子宫雌二醇受体进行了检 测, 观察到早孕大鼠子宫嗜伊红细胞雌二醇受体在数量上和分布上的变化, 而且对方法和结果 的可靠性,用竞争及对照试验给予了论证。

致谢：本工作得到世界卫生组织支持,特此致谢.

\section{参考文 献}

[1]章生艮、陈秀芳、任惠民,科学通报，27 (1982),7: 434-437.

[2] Tchernitchin, A., Steroids, 1967, 10:661-668.

[3] Lee, S. H., Histochemstry, 71 (1981), 491-500. 